\title{
Postoperative stroke after off-pump versus on-pump coronary artery bypass surgery
}

Fausto Biancari, MD, PhD, Martti Mosorin, MD, Elsi Rasinaho, MS, Jarmo Lahtinen, MD, Jouni Heikkinen, MD, Eija Niemelä, MS, Vesa Anttila, MD, PhD, Martti Lepojärvi, MD, PhD, and Tatu Juvonen, MD, PhD

Objective: The value of off-pump over conventional coronary artery bypass surgery in reducing the risk of postoperative stroke is controversial. This issue has been evaluated in light of our recent clinical experience.

Methods: Off-pump coronary artery bypass surgery was performed in 557 patients, and conventional coronary artery bypass surgery was performed in 445 patients. Preoperative stroke risk was calculated according to the Northern New England Cardiovascular Disease Study Group stroke risk-scoring method.

Results: Off-pump coronary artery bypass surgery was associated with a lower but not significant rate of postoperative stroke in the overall series $(1.8 \%$ vs $2.5 \%, P=$ .45 ), a difference that slightly increased in the highest tertile of the Northern New England Cardiovascular Disease Study Group score (2.8\% vs $4.2 \%, P=.75)$. The postoperative stroke rate was significantly lower when the operation was performed by off-pump coronary artery bypass surgeons using routinely epiaortic ultrasonographic scanning compared with conventional coronary artery bypass surgeons not using epiaortic ultrasonographic scanning $(0.4 \%$ vs $3.9 \%, P=.015)$. The Northern New England Cardiovascular Disease Study Group score (mean, $4.6 \pm 2.1$ vs $4.9 \pm$ 2.2; $P=.189$ ) was similar in these groups. Logistic regression showed that when adjusted for Northern New England Cardiovascular Disease Study Group stroke risk score and critical preoperative status, the treatment approach (off-pump coronary artery bypass surgery and routine epiaortic ultrasonographic scanning) was an independent predictor of postoperative stroke $(P=.012$; odds ratio, 34.1; 95\% confidence interval, 2.2-533.7).

Conclusions: The neuroprotective efficacy of off-pump coronary artery bypass surgery is marginal compared with that of conventional coronary artery bypass surgery. A decreased risk of postoperative stroke after off-pump coronary artery bypass surgery is expected, mostly in high-risk patients and when epiaortic ultrasonographic examination is routinely used for better planning of operative strategy, aiming to minimize the risk of intraoperative embolism.

From the Division of Cardio-thoracic and Vascular Surgery, Department of Surgery, Oulu University Hospital, Oulu, Finland.

Received for publication March 30, 2006; revisions received May 25, 2006; accepted for publication June 28, 2006.

Address for reprints: Fausto Biancari, MD, $\mathrm{PhD}$, Division of Cardio-thoracic and Vascular Surgery, Department of Surgery, Oulu University Hospital, PO Box 21, 90029 Oulu, Finland (E-mail: faustobiancari@yahoo.it and fausto.biancari@ppshp.fi).

J Thorac Cardiovasc Surg 2007;133:169-73

$0022-5223 / \$ 32.00$

Copyright () 2007 by The American Association for Thoracic Surgery

doi:10.1016/j.jtcvs.2006.06.052

$\mathrm{T}$

wo recent meta-analyses ${ }^{1,2}$ have shown that the benefit of off-pump coronary artery bypass surgery (OPCAB) over conventional coronary artery bypass surgery $(\mathrm{CCAB})$ in reducing the risk of postoperative stroke is marginal. Indeed, a significant reduction in terms of postoperative stroke can be expected only in patients at high risk of stroke and with a surgical strategy aiming to reduce the risk of intraoperative embolism. This issue has been evaluated in our recent experience when the preoperative risk of stroke was stratified according to the Northern New England Cardiovascular Disease Study Group (NNECVDSG) stroke risk score. ${ }^{3,4}$

\section{Materials and Methods}

From April 2004 through December 2005, 1016 consecutive patients underwent isolated coronary artery bypass surgery at our institution. All patients who underwent any other associated procedure were not included in the present analysis. OPCAB was performed in 539 


\begin{tabular}{|c|c|}
\hline \multicolumn{2}{|c|}{ Abbreviations and Acronyms } \\
\hline CCAB & $\begin{aligned}= & \text { conventional coronary artery bypass } \\
& \text { surgery }\end{aligned}$ \\
\hline CI & $=$ confidence interval \\
\hline NNECV & $\begin{aligned}= & \text { Northern New England Cardiovascular } \\
& \text { Disease Study Group }\end{aligned}$ \\
\hline OPCAB & $\begin{aligned}= & \text { off-pump coronary artery bypass } \\
& \text { surgery }\end{aligned}$ \\
\hline OR & $=$ odds ratio \\
\hline $\mathrm{ROC}$ & $=$ receiver operating characteristic \\
\hline TIA & $=$ transient ischemic attack \\
\hline
\end{tabular}

(53.1\%) patients, CCAB was performed in 468 (46.1\%) patients, and beating heart coronary surgery with cardiopulmonary bypass support was performed in $9(0.9 \%)$ patients.

The decision of whether to perform OPCAB or CCAB was based on the surgeon's individual choice. Although in some institutions enthusiasm for OPCAB has driven toward a complete shift from $\mathrm{CCAB}$ to $\mathrm{OPCAB}$, this did not happen in many others. In our institution as well, there are surgeons entirely committed to OPCAB opposed to surgeons entirely committed to CCAB, with a few others using both techniques according to the patient's comorbidities and coronary anatomy.

Surgeons dedicated to epiaortic ultrasonography used it on a routine basis to identify any atherosclerotic lesions of the ascending aorta. In patients with a diseased ascending aorta, the decision of whether to avoid aortic manipulation was based on the location and characteristics of the atherosclerotic lesion. Side-bite clamping was believed safe in case of flat atherosclerotic lesions located in the posterior wall of the ascending aorta or at the level of the origin of the brachiocephalic trunk far enough from the site of aortic clamping. Exophytic atherosclerotic lesions were considered an absolute contraindication to aortic manipulation. Heartstring anastomotic devices (Guidant, Indianapolis, Ind) were used in 19 patients with diseased ascending aortas. Proximal aortic connectors were used also in a few patients without diseased ascending aortas because they were included in a study evaluating the efficacy of these devices.

Stroke was defined as prolonged or permanent deficit occurring during the in-hospital stay, and it was considered the main postoperative outcome end point of this study. The overall mortality and stroke rates during the stay in our hospital were $1.5 \%$ and $2.3 \%$, respectively. The postoperative stroke rates after OPCAB, $\mathrm{CCAB}$, and beating-heart coronary surgery with cardiopulmonary bypass support were $1.9 \%, 2.6 \%$, and $11.1 \%$, respectively $(P=$ $.151)$.

We were able to calculate the NNECVDSG stroke risk score in 952 of 1016 patients because preoperative estimation of left ventricular ejection fraction was missing in 64 patients. They form the basis of the present study, and their characteristics, as well as operative data, are summarized in Table 1.

Heparin $(3.0 \mathrm{mg} / \mathrm{kg})$ was administered intravenously after sternotomy to maintain an activated clotting time of more than 400 seconds, and it was neutralized at the end of the procedure by using protamine sulfate $(3.0 \mathrm{mg} / \mathrm{kg})$. Intermittent antegrade and retro- grade cold blood cardioplegia was used during CCAB. Proximal anastomoses were sutured to the aorta during crossclamping, and aortic side clamping was never used during CCAB. Side-bite clamping was used in $437(86.2 \%)$ patients who underwent OPCAB. Proximal aortic anastomotic devices were used in 9 patients, and Heartstring anastomotic devices were used in 19 patients. The aorta was left untouched in 42 patients who underwent OPCAB. In $21(50 \%)$ of these patients, both internal thoracic artery grafts were used. Intracoronary shunts were routinely used in patients who underwent OPCAB.

Neither heparin nor warfarin was administered postoperatively in these patients unless they had atrial fibrillation. Since the policy of using anticoagulants since the first episode of atrial fibrillation was introduced in our practice at the beginning of 2004, only patients treated after that were included in this study. Acetylsalicylic acid, but not clopidogrel, was given to all patients postoperatively.

Statistical analysis was performed with SPSS statistical software (SPSS version 12.0.1; SPSS Inc, Chicago, Ill). Continuous variables are reported as the mean \pm standard deviation. The $\chi^{2}$ and Fisher exact tests were used for univariate analysis of categoric data. The Mann-Whitney test was used to assess the distribution of continuous variables in different subgroups. The receiver operating characteristic (ROC) analysis was used to assess the validity of the NNECVDSG stroke risk score. Only variables with $P$ values of less than .2 were entered into the logistic regression model.

\section{Results}

OPCAB was performed in 507 (53.3\%) patients, and conversion to $\mathrm{CCAB}$ was required in 3 patients because of hemodynamic instability. The outcome of these patients is summarized in Table 2. A significantly lower incidence of postoperative cardiac low output syndrome was observed in the OPCAB group. Otherwise, no significant difference in the other outcome end points was observed.

NNECVDSG stroke risk scores were similar in the study groups and were significantly associated with the postoperative risk of stroke (Mann-Whitney test, $P=.004$; area under the ROC curve, 0.690; 95\% confidence interval [CI], 0.590-0.789), stroke/transient ischemic attack (TIA; MannWhitney test, $P=.004$; area under the ROC curve, 0.667 ; 95\% CI, 0.577-0.757), neuropsychological complications (Mann-Whitney test, $P<.0001$; area under the ROC curve: 0.629; 95\% CI, 0.574-0.683), and stroke/TIA/neuropsychological complications (Mann-Whitney test, $P<.0001$; area under the ROC curve, 0.638; 95\% CI, 0.589-0.688). OPCAB was associated with a slightly lower rate of postoperative stroke in the overall series $(1.8 \%$ vs $2.5 \%, P=$ $.454)$, a difference that increased in the highest tertile of the NNECVDSG score $(2.8 \%$ vs $4.2 \%, P=.749$, Figure 1$)$ but failed to reach statistical significance.

Logistic regression, including critical preoperative status, recent myocardial infarction, left ventricular ejection fraction of less than $40 \%$, hypertension, history of stroke, extracardiac arteriopathy, urgent operation, and emergency 
TABLE 1. Clinical and operative data

\begin{tabular}{|c|c|c|c|c|}
\hline & Overall & OPCAB (507 patients) & CCAB (445 patients) & $P$ value \\
\hline Age (y) & $66.1 \pm 8.9$ & $65.9 \pm 8.8$ & $66.2 \pm 9.1$ & .438 \\
\hline Female sex & $207(21.7 \%)$ & $113(22.3 \%)$ & $94(21.1 \%)$ & .664 \\
\hline Diabetes & $200(21.0 \%)$ & $105(20.7 \%)$ & $95(21.3 \%)$ & .809 \\
\hline Pulmonary disease & $91(9.6 \%)$ & $51(10.1 \%)$ & $40(9.0 \%)$ & .575 \\
\hline Atrial fibrillation & $71(7.5 \%)$ & $33(6.5 \%)$ & $38(8.5 \%)$ & .234 \\
\hline Extracardiac arteriopathy & $118(12.4 \%)$ & $69(13.6 \%)$ & $49(11.0 \%)$ & .225 \\
\hline Stroke & $62(6.5 \%)$ & $35(6.9 \%)$ & $27(6.1 \%)$ & .602 \\
\hline TIA & $29(3.0 \%)$ & $11(2.2 \%)$ & $18(4.0 \%)$ & .093 \\
\hline Neurologic disease according to MCSPI & $88(9.2 \%)$ & $45(8.9 \%)$ & $43(9.7 \%)$ & .676 \\
\hline Neurologic dysfunction & $44(4.6 \%)$ & $28(5.5 \%)$ & $16(3.6 \%)$ & .158 \\
\hline Carotid endarterectomy & $19(2.0 \%)$ & $9(1.8 \%)$ & $10(2.2 \%)$ & .603 \\
\hline Current smoking & $181(19.0 \%)$ & $86(17.0 \%)$ & $95(21.3 \%)$ & .085 \\
\hline Unstable angina pectoris & $113(11.9 \%)$ & $51(10.1 \%)$ & $62(13.9 \%)$ & .065 \\
\hline Urgent operation & $439(46.1 \%)$ & $221(43.6 \%)$ & $218(49.0 \%)$ & .095 \\
\hline Recent myocardial infarction & $376(39.5 \%)$ & $179(35.3 \%)$ & $197(44.3 \%)$ & .005 \\
\hline Emergency operation & $33(3.5 \%)$ & $14(2.8 \%)$ & $19(4.3 \%)$ & .204 \\
\hline Previous cardiac surgery & $7(0.7 \%)$ & $1(0.2 \%)$ & $6(1.3 \%)$ & .055 \\
\hline Congestive heart failure & $64(6.7 \%)$ & $26(5.1 \%)$ & $38(8.5 \%)$ & .036 \\
\hline Hypertension & $425(44.6 \%)$ & $218(43.0 \%)$ & $207(46.5 \%)$ & .276 \\
\hline Critical preoperative status & $47(4.9 \%)$ & $17(3.4 \%)$ & $30(6.7 \%)$ & .016 \\
\hline Intra-aortic balloon pump & $5(0.5 \%)$ & $3(0.6 \%)$ & $2(0.4 \%)$ & 1.00 \\
\hline Ventricular septal rupture & $0(0 \%)$ & $0(0 \%)$ & $0(0 \%)$ & - \\
\hline Creatinine $(\mathrm{mg} / \mathrm{dL})$ & $79.6 \pm 32.7$ & $79.4 \pm 31.8$ & $79.8 \pm 33.7$ & .851 \\
\hline Renal failure & $8(0.8 \%)$ & $3(0.6 \%)$ & $5(1.1 \%)$ & .484 \\
\hline Left ventricular ejection fraction & & & & .025 \\
\hline$\geq 50 \%$ & $753(82.3 \%)$ & $418(85.3 \%)$ & $335(78.8 \%)$ & \\
\hline $30 \%-40 \%$ & $131(3.4 \%)$ & $56(11.4 \%)$ & $75(17.6 \%)$ & \\
\hline$<30 \%$ & $31(3.4 \%)$ & $16(3.3 \%)$ & $15(3.5 \%)$ & \\
\hline Aortic connector devices & $9(0.9 \%)$ & $9(1.8 \%)$ & $0(0 \%)$ & .004 \\
\hline Heartstring anastomosis devices & $19(2.0 \%)$ & $19(3.7 \%)$ & $0(0 \%)$ & $<.0001$ \\
\hline LITA & $931(97.8 \%)$ & $500(98.6 \%)$ & $431(96.9 \%)$ & .064 \\
\hline RITA & $58(6.1 \%)$ & $40(7.9 \%)$ & $18(4.0 \%)$ & .013 \\
\hline Radialis artery graft & $380(39.9 \%)$ & $233(46.0 \%)$ & $147(33.0 \%)$ & $<.0001$ \\
\hline Vein graft & $834(87.6 \%)$ & $417(82.2 \%)$ & $417(93.7 \%)$ & $<.0001$ \\
\hline Gastroepiploic artery & $2(0.2 \%)$ & $1(0.2 \%)$ & $1(0.2 \%)$ & 1.0 \\
\hline No. of distal anastomoses & $3.7 \pm 0.9$ & $3.5 \pm 0.9$ & $4.0 \pm 0.9$ & $<.0001$ \\
\hline No. of proximal aortic anastomoses & $1.8 \pm 0.7$ & $1.6 \pm 0.7$ & $2.1 \pm 0.6$ & $<.0001$ \\
\hline Mean NNECVDSG stroke risk score & $4.7 \pm 2.2$ & $4.6 \pm 2.2$ & $4.7 \pm 2.2$ & .355 \\
\hline Median NNECVDSG stroke risk score* & $5.0(3.5-6.0)$ & $5.0(3.5-6.0)$ & $4.5(3.5-6.5)$ & .355 \\
\hline
\end{tabular}

Continuous variables are reported as the mean \pm standard deviation. Risk factors are reported according to the EuroSCORE criteria. OPCAB, Off-pump coronary artery bypass surgery; CCAB, conventional coronary artery bypass surgery; TIA, transient ischemic attack; LITA, left internal thoracic artery; RITA, right internal thoracic artery; NNECVDSG, Northern New England Cardiovascular Disease Study Group. *Median (25th and 75th percentile).

operation, showed that critical preoperative status was the only independent predictor of postoperative stroke $(P=$ .001 ; odds ratio $[\mathrm{OR}], 6.246 ; 95 \% \mathrm{CI}, 2.145-18.194$; Hosmer-Lemeshow test, $P=.588$ ). When the NNECVDSG stroke risk score was included in the regression model, critical preoperative status maintained its significance $(P<.0001$; OR, 6.607; 95\% CI, 2.303-18.961), and NNECVDSG score was also an independent predictor of postoperative stroke $(P=.024$; OR, $1.285 ; 95 \% \mathrm{CI}$, 1.034-1.598).
We compared the results of 3 surgeons with a prevalent ( $>80 \%$ of cases) OPCAB approach using routinely epiaortic ultrasonographic scanning (228 patients) with those of 3 surgeons with a prevalent ( $>79 \%$ of cases) $\mathrm{CCAB}$ approach not using epiaortic ultrasonographic scanning (204 patients). The other surgeons were not considered in this subanalysis because they do not routinely use epiaortic ultrasonography, they perform $\mathrm{CCAB}$ and $\mathrm{OPCAB}$ with a similar prevalence, or both. The NNECVDSG score was similar in these groups (mean, $4.6 \pm 2.1$ vs $4.9 \pm 2.2$; 
Table 2. Postoperative complications

\begin{tabular}{|c|c|c|c|c|}
\hline & Overall & ОРСАВ & CCAB & $P$ value \\
\hline In-hospital mortality & $12(1.3 \%)$ & $6(1.2 \%)$ & $6(1.3 \%)$ & .820 \\
\hline Stroke & $20(2.1 \%)$ & $9(1.8 \%)$ & $11(2.5 \%)$ & .454 \\
\hline Transient ischemic attack & $6(0.6 \%)$ & $3(0.6 \%)$ & $3(0.7 \%)$ & 1.00 \\
\hline Neuropsychological complications requiring treatment & $106(11.1 \%)$ & $63(12.4 \%)$ & $43(9.7 \%)$ & .176 \\
\hline Atrial fibrillation & $361(37.9 \%)$ & $186(36.7 \%)$ & $175(39.3 \%)$ & .402 \\
\hline Pneumonia & $67(7.0 \%)$ & $29(5.7 \%)$ & $38(8.5 \%)$ & .090 \\
\hline Renal failure requiring dialysis & $8(0.8 \%)$ & $3(0.6 \%)$ & $5(1.1 \%)$ & .484 \\
\hline Postoperative bleeding requiring reoperation & $34(3.6 \%)$ & $17(3.4 \%)$ & $17(3.8 \%)$ & .698 \\
\hline Low cardiac output & $91(9.6 \%)$ & $38(7.5 \%)$ & $53(11.9 \%)$ & .021 \\
\hline Postoperative intra-aortic balloon pump & $9(0.9 \%)$ & $4(0.8 \%)$ & $5(1.1 \%)$ & .741 \\
\hline
\end{tabular}

$O P C A B$, Off-pump coronary artery bypass surgery; $C C A B$, conventional coronary artery bypass surgery.

median, 4.8 vs $5.0 ; P=.189)$. The postoperative stroke rate in the OPCAB group was $0.4 \%$, and it was $3.9 \%$ in the CCAB group $(P=.015)$, whereas the postoperative stroke/ TIA rates were $1.3 \%$ versus $3.9 \%(P=.125)$. Logistic regression showed that even when adjusted for NNECVDSG stroke risk score and critical preoperative status (both maintained their independent prognostic value), the treatment approach was an independent predictor of postoperative stroke $(P=.012$; OR, 34.135; 95\% CI, 2.183533.746; Hosmer-Lemeshow test, $P=.507)$. The number of distal anastomoses $(3.6 \pm 0.9$ vs $3.7 \pm 0.9, P=.73)$ was similar in these study groups, whereas the number of proximal anastomoses to the aorta $(1.7 \pm 0.7$ vs $1.9 \pm 0.6, P=$ .009) was lower in the OPCAB group. The ascending aorta was left untouched in $18(7.9 \%)$ patients operated on by

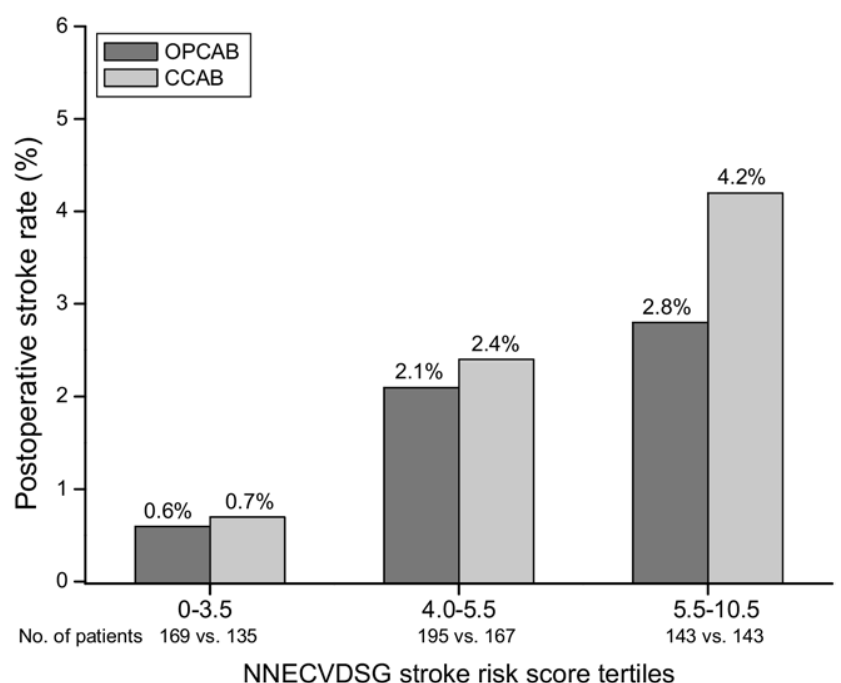

Figure 1. Risk of in-hospital stroke after off-pump coronary artery bypass surgery (OPCAB) versus conventional coronary artery bypass surgery (CCAB) according to the Northern New England Cardiovascular Disease Study Group (NNECVDSG) stroke risk score tertiles. these $3 \mathrm{OPCAB}$ surgeons. In $5(2.5 \%)$ patients who underwent $\mathrm{CCAB}$, no proximal anastomoses were carried out. Surgeons committed to OPCAB have used Heartstring proximal aortic anastomotic devices in 13 patients. These devices have never been used by surgeons committed to $\mathrm{CCAB}$ in this series.

\section{Discussion}

The results of this relatively small study suggest that patients at high risk of postoperative stroke, as identified by using the NNECVDSG scoring method, would most benefit from undergoing OPCAB. However, such a difference is not likely to become significant without an appropriate strategy aiming to reduce intraoperative embolism to the brain. In fact, the benefits of this minimally invasive treatment must be optimized by means of routine intraoperative ultrasonographic examination of the ascending aorta and, when indicated, avoidance of aortic manipulation to avoid dangerous side clamping of a diseased aorta. ${ }^{5}$

However, the risk of postoperative stroke does not completely vanish, even after a carefully planned and performed operation. In fact, even if the exact day of occurrence of stroke is not always clear because some patients are intubated and sedated for several days after surgical intervention, preoperative stroke might suddenly occur a few days after the operation, complicating an apparently normal postoperative recovery (Figure 2) ${ }^{6-8}$ This suggests that other causes of stroke occurring after the first postoperative day must be advocated. Embolism from the left atrium and ventricle, as well as extracranial and intracranial vascular disease, might be causes of such late strokes. In this study postoperative atrial fibrillation was not associated with the occurrence of postoperative stroke $(P=.226)$, likely because of our current policy to administer anticoagulants since the first episode of atrial fibrillation. Because the benefits of concurrent carotid endarterectomy are still to be demonstrated, ${ }^{9}$ probably embolism from the left cavities of the heart is the main causative mechanism of such late 


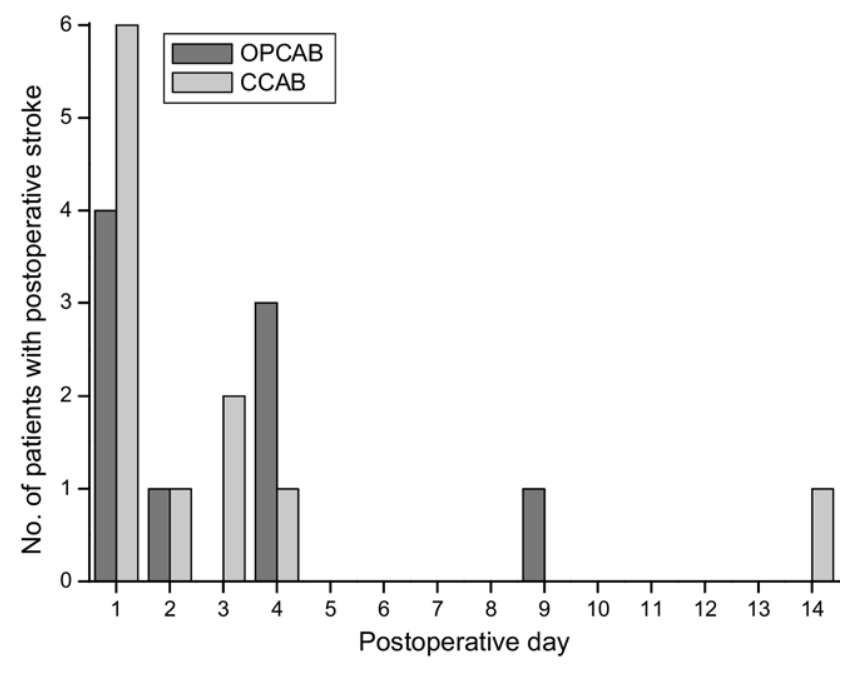

Figure 2. Chronologic distribution of postoperative stroke according to type of operation. OPCAB, Off-pump coronary artery bypass surgery; $C C A B$, conventional coronary artery bypass surgery.

stroke. We also suspect that in a few patients paradoxical embolism through a patent foramen ovale defect might occur because asymptomatic pulmonary embolism after coronary artery surgery is not uncommon. ${ }^{10}$ This means that to further reduce the risk of stroke, anticoagulation during the in-hospital period should be considered in high-risk patients.

We believe that further comparative analyses on this issue cannot be appropriately performed if patients' stroke risk is not stratified according to specific risk-scoring methods. In fact, this makes possible a more adequate comparison of the results between different surgical strategies and evaluation of any possible difference between different institutions. Indeed, the results of a series of patients with a median NNECVDSG score ranging from 1.1 to $1.5^{5}$ are not comparable with those of the present series, in which the overall median score was 5.0. Similarly, the characteristics and possibly the mechanisms leading to stroke in patients with a median NNECVDSG score of $2.8^{7}$ can be different from those of the ones herein reported, whose median score was 5.8 .

In conclusion, the neuroprotective efficacy of OPCAB is marginal compared with that of CCAB. However, a decreased risk of postoperative stroke after OPCAB is expected, mostly in high-risk patients and when epiaortic ultrasonographic examination is routinely used for better planning of operative strategy, aiming to minimize the risk of intraoperative embolism.

\section{References}

1. Wijeysundera DN, Beattie S, Djaiani G, Rao V, Borger MA, Karkouti $\mathrm{K}$, et al. Off-pump coronary artery surgery for reducing mortality and morbidity. Meta-analysis of randomized and observational studies. J Am Coll Cardiol. 2005;46:872-82.

2. Cheng DC, Bainbridge D, Martin JET, Novick RJ, The Evidencebased Perioperative Clinical Outcomes Research Group. Does offpump coronary artery bypass reduce mortality, morbidity and resource utilization when compared with conventional coronary artery bypass? A meta-analysis of randomized trials. Anesthesiology. 2005;102:188203.

3. Charlesworth DC, Likosky DS, Marrin CAS, Maloney CT, Quinton $\mathrm{HB}$, Morton JR, et al. Development and validation of a prediction model for stroke after coronary artery bypass surgery. Ann Thorac Surg. 2003;76:436-43.

4. Kangasniemi OP, Luukkonen J, Biancari F, Leo E, Vuorisalo S, Pokela R, et al. Risk scoring methods for prediction of postoperative stroke after coronary artery bypass surgery. J Thorac Cardiovasc Surg. 2006;131:734-5.

5. Kapetanakis EI, Stamou SC, Dullum MKC, Haile E, Boyce SW, Bafi AS, et al. The impact of aortic manipulation on neurologic outcomes after coronary artery bypass surgery: a risk-adjusted study. Ann Thorac Surg. 2004;78:1564-71.

6. Likosky DS, Marrin CAS, Caplan LR, Baribeau YR, Morton JR, Weintraub RM, et al. Determination of etiologic mechanisms of strokes secondary to coronary artery bypass graft surgery. Stroke. 2003;34:2830-4.

7. Peel GK, Stamou SC, Dullum MKC, Hill PC, Jablonski KA, Bafi AS, et al. Chronologic distribution of stroke after minimally invasive versus conventional coronary artery bypass. J Am Coll Cardiol. 2004; 43:752-6.

8. Lahtinen J, Biancari F, Salmela E, Mosorin M, Satta J, Rainio P, et al. Postoperative atrial fibrillation is a major cause of stroke after onpump coronary artery bypass surgery. Ann Thorac Surg. 2004;77: $1241-4$.

9. Ricotta JJ, Wall LP, Blackstone E. The influence of concurrent carotid endarterectomy on coronary bypass: a case-controlled study. J Vasc Surg. 2005;41:397-401.

10. Lahtinen J, Ahvenajärvi L, Biancari F, Ojala R, Mosorin M, Cresti R, et al. Pulmonary embolism after off-pump coronary artery bypass surgery as detected by computed tomography. Am J Surg. 2006;192: 396-8. 